\title{
Synthesis of ureasil-polyether film forming materials by using environmentally friendly solvent
}

Juliana Fernandes Mendes¹, João Augusto Oshiro Junior ${ }^{1}$, Camila Garcia da Silva', Leila Aparecida Chiavacci ${ }^{1 *}$

'Pharmaceutical Sciences School, Universidade Estadual Paulista (UNESP), Araraquara, SP, Brasil

*Corresponding author: leila.chiavacci@unesp.br

\begin{abstract}
Organic inorganic hybrids present several advantages as drug release systems, such as: high flexibility, high mechanical and thermal resistance, transparency, and low water solubility. These hybrids are synthesized through a chemical route named sol-gel that usually uses as solvente tetrahydrofuran (THF). Objetives: To develop film formers from hybrid materials replacing THF with ethanol, a less toxic solvent for skin application and for the environment. Methods: Four polymers were used: two based on polyethylene oxide (PEO) with molecular weight of 500 and $1900 \mathrm{~g} \mathrm{~mol}-1$ and two based on polypropylene oxide (PPO), with molecular weight of 400 and 2000 $\mathrm{g}$ mol-1. The structural analysis was performed by FTIR, 1H-NMR and 29Si-NMR, and the thermalmechanical analysis by DSC and TG-DTA. Results: The results of the thermo-mechanical analysis revealed that the solvent replacement did not affect the thermal stability and flexibility of the diureasil hybrid. Conclusions: Structural characterization confirmed the formation of hybrids both in THF and in ethanol. Therefore, ethanol is an excellent solvent for the synthesis of these hybrid matrices, since it allows obtaining the same material without changing its characteristics, with some advantages, however, over THF. Furthermore, this paper describes the efficiency of ethanol as a solvent, which is environmentally friendly, to replace THF in the physical-chemical characteristics of these filming former materials.
\end{abstract}

Keywords: Organic-inorganic hybrids, sol-gel process, film formers, structural analysis, thermal analysis, ethanol, mechanical analysis.

\section{How to cite}

Mendes JF, Oshiro Junior JA, Silva CG, Chiavacci LA. Synthesis of ureasil-polyether film forming materials by using environmentally friendly solvent. Rev Ciênc Farm Básica Apl. 2021;42:e730. https://doi.org/10.4322/2179-443X.0730.

\section{INTRODUCTION}

The interest in different fields in new technologies for controlled release has been increasing in recent years, as these systems have advantages over conventional ${ }^{1-4}$ ones, such as reduced toxicity, prolonged time in the bloodstream, gradual and controlled release of the drug, safe and adequate administration, targeting to specific organs, and the ability to incorporate hydrophilic and lipophilic substances ${ }^{5,6}$.

Financial support: FAPESP - Fundação de Amparo à Pesquisa do Estado de São Paulo or Foundation for Research Support of the State of São Paulo, process number 2017/21456-3. CAPES - Coordenação de Aperfeiçoamento de Pessoal de Nível Superior - Brasil (CAPES) - Finance Code 001.

Conflicts of interest: There is no conflict of interest.

The study was carried out at Pharmaceutical Sciences School, Universidade Estadual Paulista (UNESP), Araraquara, SP, Brasil. Received on March 15, 2021. Accepted on May 26, 2021. 
Some modifications at the nanometric structure of polymeric materials offer optimization of structural, optical and mechanical characteristics with great application for controlled release of drugs. Among the new class of nanostructured polymers, one can highlight the organic-inorganic hybrid materials ${ }^{7}$, in particular, di-ureasil hybrids, which are biocompatible, transparent and flexible, and present better mechanical properties than pure polyethers ${ }^{8}$. The transparency is a feature desired in some pharmaceuticals and cosmetics systems, as it increases patient acceptability and allows the physician to monitor the healing process.

These hybrids are synthesized and processed through the chemical route known as solgel $^{9-12}$. During the synthesis of precursors, the usually employed solvent is tetrahydrofuran (THF), which is widely used industrially. Several human studies show that THF is readily absorbed from the respiratory tract. Moreover, this solvent is absorbed through the skin and the THF vapors may cause irritation of mucous membranes, respiratory system and skin ${ }^{13,14}$. Ong et al. ${ }^{15}$ reported that occupational exposures (inhalation and dermal) to THF resulted in measurable blood and urine THF levels. As a result of its industrial uses, THF may enter the environment through industrial waste streams and if it is accidentally released in soil or water, precipitating some volatilization to the atmosphere. In addition, THF is more expensive than ethanol and, in Brazil, THF is controlled by the Federal Police, which complicates its use on an industrial scale, as well as its acquisition.

Therefore, in this work, we show that ethanol, an environmentally friendly solvent, can be successfully employed in replacing THF in the synthesis of ureasil-polyether film forming hybrids.

\section{MATERIALS AND METHODS}

\subsection{Materials}

3-(Trithoxysilyl)Propyl Isocyanate (ICPTES), 95\%, Sigma-Aldrich, [O,O'bis(2- aminopropyl)polypropyleneglycol-block-polyethyleneglycol-block-polypropylene glycol] (PEO, Mw= 500 and $1900 \mathrm{~g} \cdot \mathrm{mol}^{-1}$ ) and [Poly(propylene glycol)bis(2-aminopropyl ether)] (PPO, $\mathrm{Mw}=400$ and $\left.2000 \mathrm{~g} \cdot \mathrm{mol}^{-1}\right)$, Sigma Aldrich were used without prior purifications. The solvents Tetrahydrofuran $99.9 \%$, Sigma Aldrich and ethanol 99.5\%, Synth were used to promote hybrid precursor molecule formation. An aqueous solution of $\mathrm{HCl} 37 \%$, Synth, was used to catalyze the hydrolysis and condensation reactions..

\subsection{Synthesis of the polyether-ureasil precursors (hybrid precursors)}

The preparation of the di-ureasil hybrids precursors involved the formation of a covalent urea linkage between the terminal aminopropyl groups of the functionalized PEO or PPO and the isocyanate group of the ICPTES (Step 1 of the Scheme 1). In a typical procedure, the functionalized PEO or PPO was dissolved in THF or ethanol (amounts described in Table 1) and added to a three-necked round-bottomed flask equipped with a mechanical stirrer, and reflux condenser. Then, ICPTES was introduced with a molar ratio of 1:2, and the mixtures were stirred and refluxed for $24 \mathrm{~h}$. The solvent (THF and ethanol) was eliminated by evaporation under vacuum at $80^{\circ} \mathrm{C}\left( \pm 10^{\circ} \mathrm{C}\right)$, leading to the formation of the hybrid precursors. The nomenclatures U-PEO500, U-PEO1900, U-PPO400 and U-PPO2000 were adopted to identify the final precursors prepared using ethanol (ET) or THF as solvents.

Table 1. Amount of reagents used in the synthesis of hybrid matrices.

\begin{tabular}{|c|c|c|c|}
\hline \multirow{2}{*}{ Hybrid matrices } & \multirow{2}{*}{ ICPTES (mL) } & $\mathrm{NH}_{2}-\mathrm{PEO}-\mathrm{NH}_{2}$ or & \multirow{2}{*}{ THF/Ethanol (mL) } \\
\hline & & $\mathrm{NH}_{2}-\mathrm{PPO}-\mathrm{NH}_{2}$ (g) & \\
\hline U-PEO 500 & 19.6 & 25 & 100 \\
\hline U-PEO 1900 & 6.3 & 25 & 40 \\
\hline U-PPO 400 & 34.3 & 25 & 80 \\
\hline U-PPO 2000 & 6.0 & 25 & 40 \\
\hline
\end{tabular}




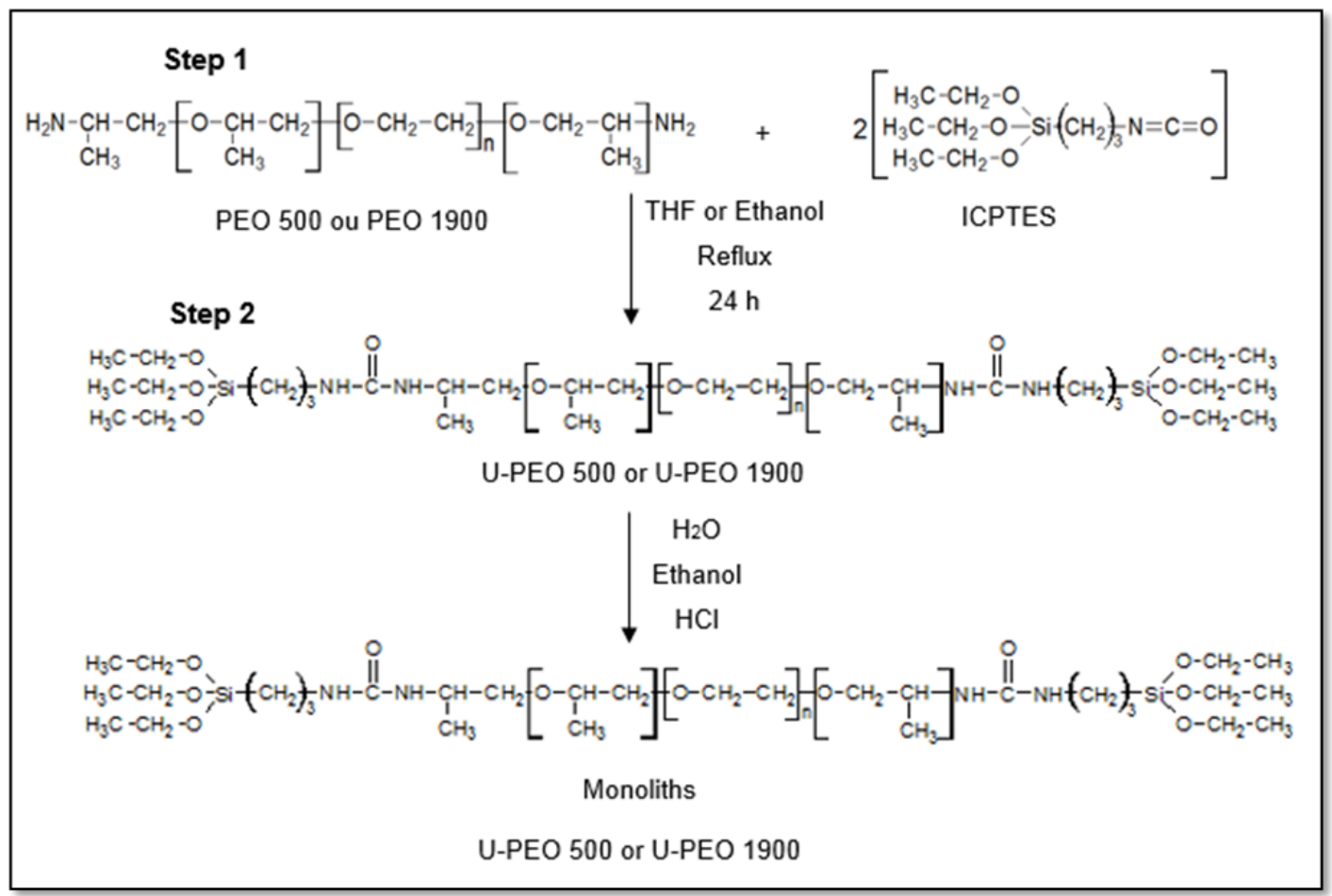

Scheme 1. Schematic representation of the synthesis of U-PEO500 and U-PEO1900 hybrids monoliths. (A similar process was adopted for the synthesis of U-PPO400 and U-PPO2000 hybrid monoliths).

\subsection{Preparation of the monoliths}

The second step (Step 2 of Scheme 1) comprised the hydrolysis of $\mathrm{Si}\left(\mathrm{OCH}_{2} \mathrm{CH}_{3}\right)_{3}$ to generate silanol moieties, followed by condensation reactions to form di-ureasil hybrid monoliths. The hydrolysis reaction was initialized by adding $500 \mu \mathrm{L}$ of ethanol, $50 \mu \mathrm{L}$ of water and $36 \mu \mathrm{L}$ of $\mathrm{HCl}$ as catalyst to $0.75 \mathrm{~g}$ of the di-ureasil precursors. Finally, monoliths were obtained after drying under vacuum at $70^{\circ} \mathrm{C}$ for $24 \mathrm{~h}$.

\subsection{Characterizations of hybrid precursors and monoliths}

FTIR spectra of hybrid precursors and monoliths were registered from their thin film cast onto $\mathrm{NaCl}$ windows and $\mathrm{KBr}$ pellets, respectively, using a Perkin Elmer Spectrum 2000 in transmittance mode. The analysis was done in the $4000-370 \mathrm{~cm}^{-1}$ region and at resolution of $1 \mathrm{~cm}^{-1}$.

The ${ }^{1} \mathrm{H}-\mathrm{NMR}$ spectra of functionalized POE and PPO and hybrid precursors were recorded in a Varian $(500 \mathrm{MHz})$ using $\mathrm{CDCl}_{3}$ as solvent. The spectra ${ }^{29} \mathrm{Si}-\mathrm{NMR}$ of monoliths were recorded in a Varian $(300 \mathrm{MHz})$. The following parameters were fixed: spectral width of $100 \mathrm{kHz}$; pulse of $101.2^{\circ}$; relaxation of 30 s and line broadening in $50 \mathrm{~Hz}$.

The monoliths were also characterized by TG and DSC. TG were performed using a TA-SDT Q600 instrument and the samples were heated to $980^{\circ} \mathrm{C}$ with a heating rate of $5^{\circ} \mathrm{C} / \mathrm{min}$ under nitrogen flow. The glass transition, melt temperatures and transition enthalpies of hybrid monoliths were measured using the TA-DSC Q100 equipment with the temperature ranging from $-90^{\circ} \mathrm{C}$ to $350^{\circ} \mathrm{C}$ and heating rate of $10^{\circ} \mathrm{C} / \mathrm{min}$ under nitrogen atmosphere.

The DMA technique was used to determine the mechanical strength of the hybrid matrix. The measurements were performed using a TA-DMA 2980, operating at room temperature, with a variation ramp force of $1 \mathrm{~N} / \mathrm{min}$ to $18 \mathrm{~N}$, static force of $0.02 \mathrm{~N}$, compression load mode and samples in a cylindrical shape with $6.25 \mathrm{~mm}$ diameter. 


\section{RESULTS AND DISCUSSION}

\subsection{Synthesis and characterization of hybrid precursors}

Figure 1 shows the FTIR spectra of di-ureasil precursors prepared as previously described. The absorption band of isocyanate groups $(\mathrm{N}=\mathrm{C}=\mathrm{O})$ of ICPTES at around $2274 \mathrm{~cm}^{-1}$ disappeared, indicating that this group reacted completely with $\mathrm{N}-\mathrm{H}$ groups of functionalized PEO and PPO to form urea bridges in both solvents. The presence of urea linkages $(-\mathrm{NHC}(=\mathrm{O}) \mathrm{NH}-)$ in all precursors was confirmed by bands in the amide I and II region. The amide I region in the FTIR spectra of all di-ureasil precursors showed a weak band at $1720 \mathrm{~cm}^{-1}$ assigned to free carbonyl band and an intense band with maximum range from 1630 to $1660 \mathrm{~cm}^{-1}$ associated with the hydrogen-bonded carbonyl band. Indeed, a strong band in the amide II region of these spectra at about $1560 \mathrm{~cm}^{-1}$ ascribed to $\mathrm{N}-\mathrm{H}$ in-plane blending and C-N stretching. In addition, two broad bands appeared at about 3330 and $3530 \mathrm{~cm}^{-1}$, which were attributed to "free" and hydrogen-bonded stretching vibration of N-H groups of urea, respectively. The last band was less intense than the first one for all precursors with the exception of those prepared using Jeffamine ED2003. Bands attributed to ethoxysilane groups $\left(\mathrm{Si}-\mathrm{OCH}_{2} \mathrm{CH}_{3}\right)$ are characterized by strong doublets at $1100-1075 \mathrm{~cm}^{-1}$ and less intense bands at around 1170 and $950 \mathrm{~cm}^{-1}$. Unfortunately, these bands appear in the same region of C-C and $\mathrm{C}-\mathrm{O}$ stretching and $\mathrm{CH}_{2}$ angular deformation of functionalized PEO and PPO backbones and then the presence of ethoxysilane groups in the di-ureasil precursors cannot be confirmed in their FTIR spectra.
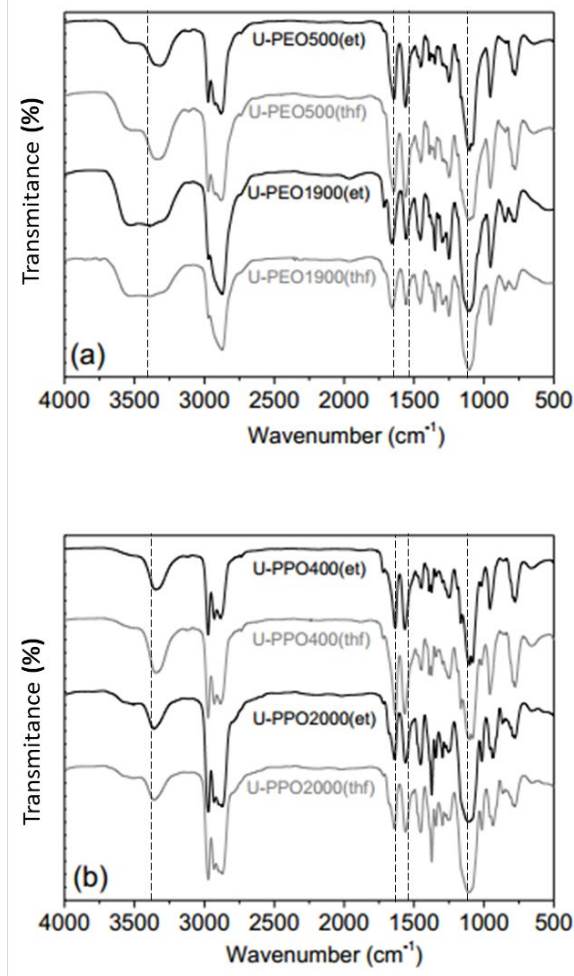

Figure 1. FTIR spectra of di-ureasil precursors prepared by using THF and ethanol as solvent (a) U-PEO and (b) U-PPO.

The molecular structures of di-ureasil precursors are also confirmed by the ${ }^{1} \mathrm{H}$ NMR technique. Figures 2 and 3 show the ${ }^{1} \mathrm{H}$ NMR spectra of U-PEO and U-PPO precursors, respectively, prepared with different molecular weight using THF and ethanol solvents. The signals of functionalized PEO and PPO backbone can be assigned as follows: methyl groups 
(- $\left.\mathrm{O}-\mathrm{CH}\left(-\mathrm{CH}_{3}\right)-\mathrm{CH}_{2}-\right)$ at 1.05 ppm, methylene groups (-O- $\left.\mathrm{CH}\left(-\mathrm{CH}_{3}\right)-\mathrm{CH}_{2}-\right)$ at 3.31-3.49 ppm and methyne groups $\left(-\mathrm{O}-\mathrm{CH}\left(-\mathrm{CH}_{3}\right)-\mathrm{CH}_{2}-\right)$ at $3.0 \mathrm{ppm}$ attributed to propylene units present in backbone of all PEO and PPO, and methylene groups $\left(-\mathrm{O}-\mathrm{CH}_{2}-\mathrm{CH}_{2}-\right)$ at $3.56 \mathrm{ppm}$ from ethylene units present in backbone of the functionalized PEO. The presence of ethoxysilane groups was confirmed by the intense signals at $1.18 \mathrm{ppm}\left(-\mathrm{Si}-\mathrm{O}-\mathrm{CH}_{2} \mathrm{CH}_{3}\right)$ and $3.65 \mathrm{ppm}\left(-\mathrm{Si}-\mathrm{O}-\mathrm{CH}_{2} \mathrm{CH}_{3}\right)$, showing that hydrolysis of these groups did not occur during the reaction. Furthermore, the methylene groups linked next to silicon atoms $\left(-\mathrm{Si}_{-}-\mathrm{CH}_{2}-\mathrm{CH}_{2}-\right)$ appear at 0.55 and 0.77 for $\mathrm{U}-\mathrm{PEO}$ and UPPO, respectively. The next methylene groups (-Si- $\left.\mathrm{CH}_{2}-\mathrm{CH}_{2}-\right)$ showed a signal at $1.50 \mathrm{ppm}$ for all precursors. However, the signal of methylene groups linked next to urea bridges are covered by methylene groups of propylene units at around $3.0 \mathrm{ppm}$.
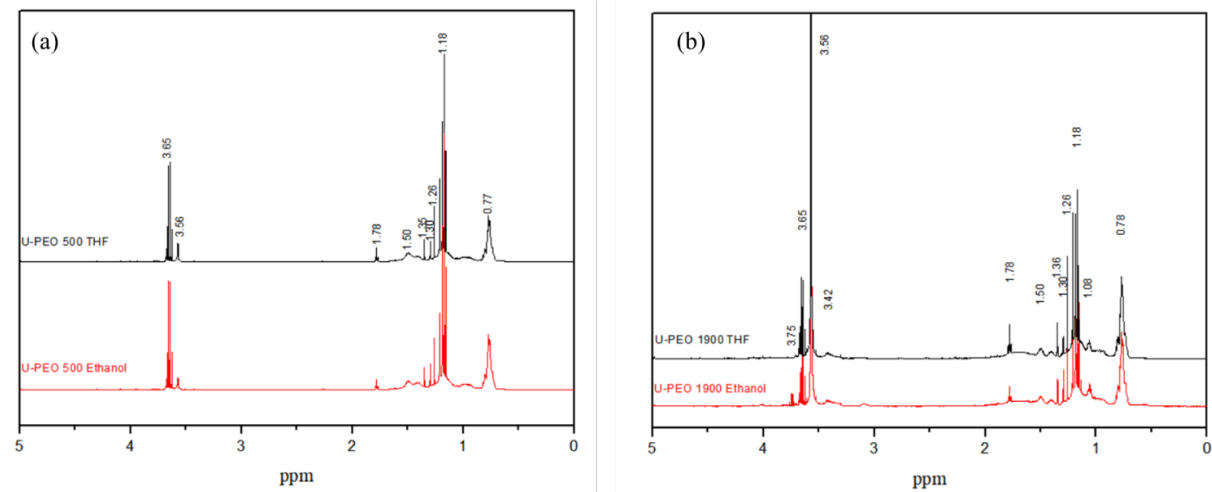

Figure 2. ${ }^{1} \mathrm{H}$ NMR spectra of U-PEO500 (a) and U-POE1900(b) hybrid precursors prepared with THF and ethanol solvents.
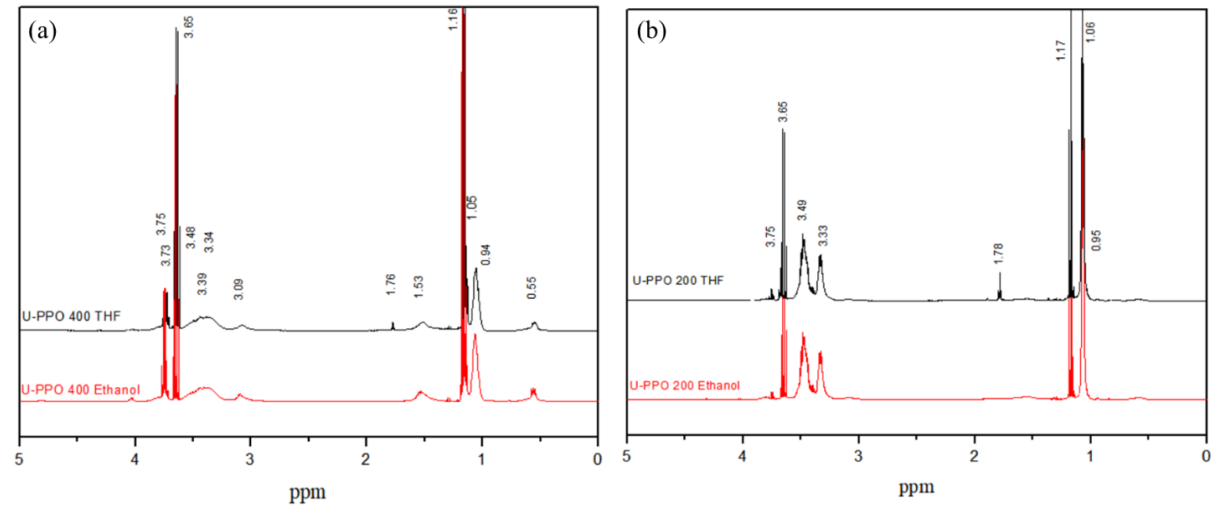

Figure 3. ${ }^{1} \mathrm{H}$ NMR spectra of U-PPO400 (a) and U-PPO2000(b) hybrid precursors prepared with THF and ethanol solvents.

\subsection{Characterizations of monoliths}

\subsubsection{Structural characterization}

Figure 4 shows the hybrid monoliths prepared using all di-ureasil precursors. The transparency of these monoliths is a result of the nanostructural uniformity of the network produced by the organic-inorganic hybrid approach. FTIR spectra of these monoliths are presented in Figure $5 a$ and $b$. 


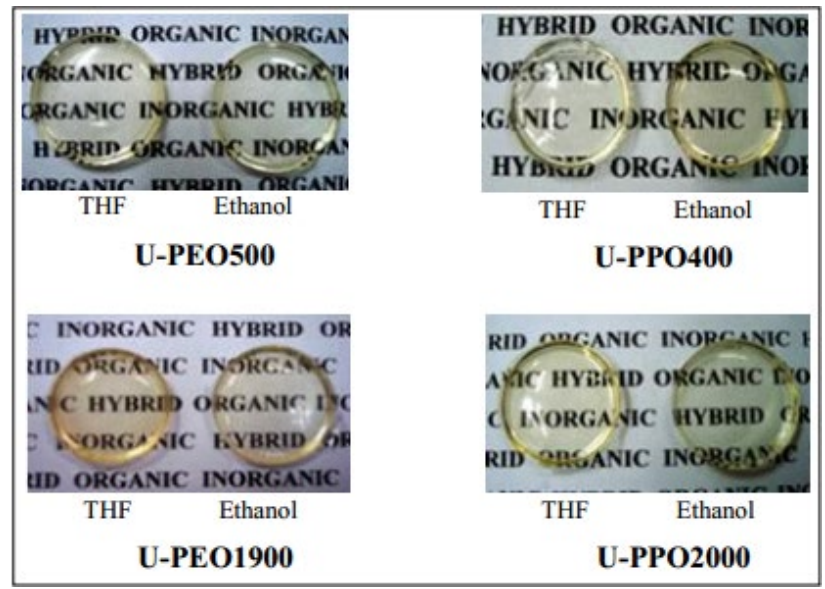

Figure 4. Images of hybrids monoliths prepared using di-ureasil precursors synthesized in THF and ethanol.
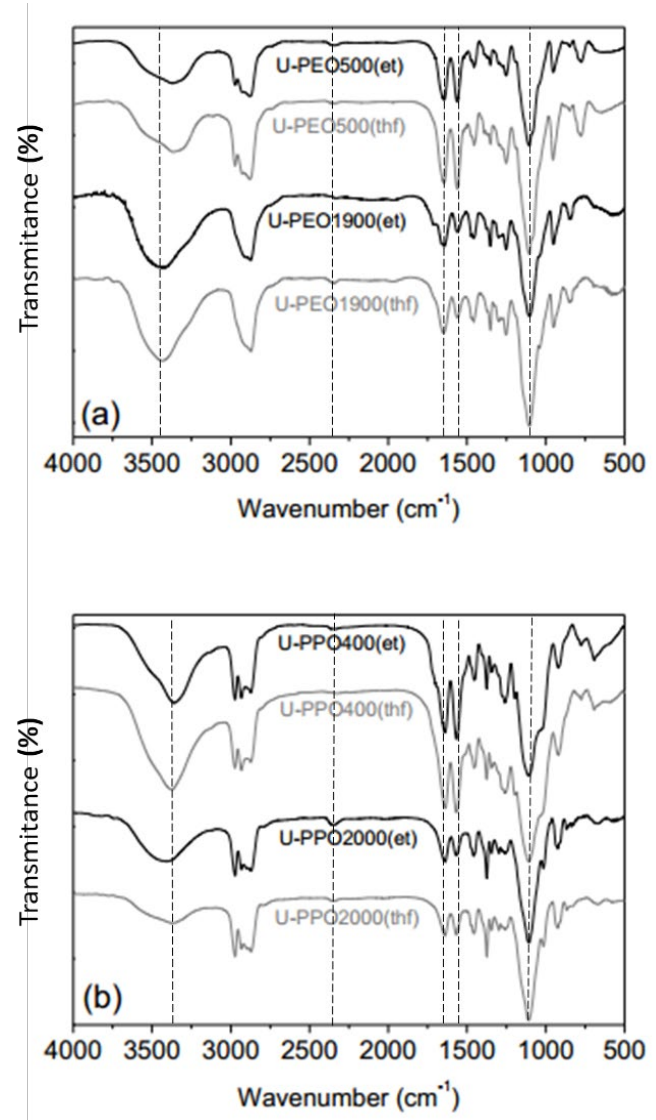

Figure 5. FTIR spectra of monoliths prepared from di-ureasil precursors (a) U-PEO and (b) U-PPO with THF and ethanol.

The use of different solvents and functionalized polymers to synthetize the di-ureasil precursors did not influenced on FTIR spectra of their respective monoliths. The most intense bands in these spectra appeared at about $1100 \mathrm{~cm}^{-1}$ and it was attributed to the C-O stretching of oxyethylene units. The presence of urea linkages in these monoliths are confirmed by bands at amide I and II regions. The band at $1640 \mathrm{~cm}^{-1}$ in all spectra is attributed to amide I mode ( $\mathrm{C}=\mathrm{O}$ and $\mathrm{C}-\mathrm{N}$ stretch and $\mathrm{C}-\mathrm{C}-\mathrm{N}$ deformation vibrations) associated to more ordered hydrogen-bonded aggregated (e.g., urea/urea association). However, the spectrum of U- PEO1900(et) showed other amide I components at $1715 \mathrm{~cm}^{-1}$ that are assigned to the 
absorption of hydrogen-bonded $\mathrm{C}=\mathrm{O}$ in disordered aggregates. Amide II band appears at $1560 \mathrm{~cm}^{-1}$, and the $\mathrm{N}-\mathrm{H}$ stretching of urea linkage is centered at about $3450-3360 \mathrm{~cm}^{-1}$ in these FTIR spectra. The shift of the N-H stretching band can be attributed to intermolecular hydrogen bonding. In addition, the intensities of amide I and II in relation to C-O stretching band of oxyethylene units are affected by average molecular weights of functionalized polymers. The amide I and II bands of U-PEO500 and U-PPO400 are more intense than those of U-PEO1900 and U-PPO2000 due to the presence of more oxyethylene units in the backbone of the last two.

Figure 6 presents ${ }^{29} \mathrm{Si}$ NMR spectrum of monoliths, in which it was possible to observe the presence of peaks between -59 and $-67 \mathrm{ppm}$, which are assigned to the species $\mathrm{T}_{2}\left(\mathrm{RSi}(\mathrm{OSi})_{2}(\mathrm{OH})\right)$ and $\mathrm{T}_{3}\left(\mathrm{RSi}(\mathrm{OSi})_{3}\right.$, respectively ${ }^{16}$. Table 2 shows that the hybrid matrices presented a high degree of polycondensation (above 85\%), revealing the existence of few terminal $\mathrm{OH}$ groups in the structure of these materials. This fact has also been shown in previous works, with U-PEO500 and U-PEO1900 being synthesized with THF from basic or acid catalysis ${ }^{9,11}$.
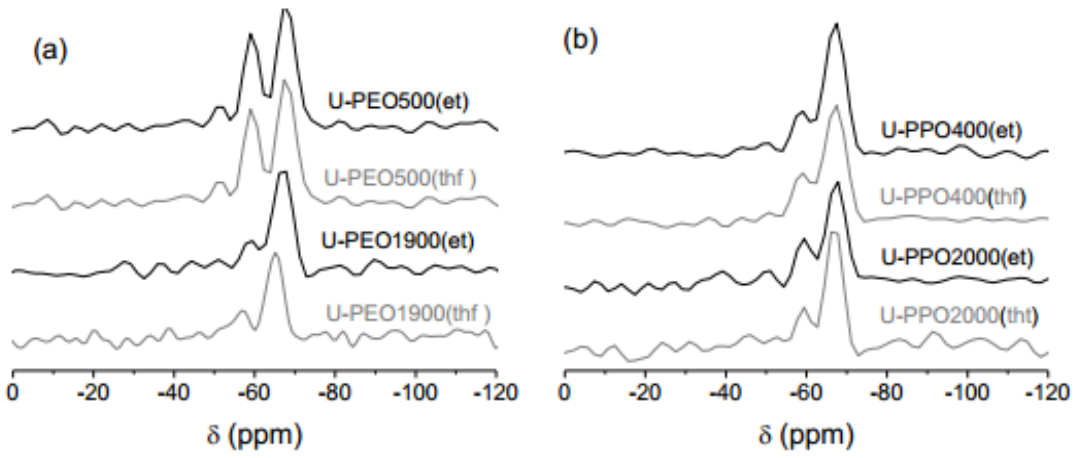

Figure 6. ${ }^{29} \mathrm{Si}$ NMR spectrum of monoliths from di-ureasil precursors (a) U-PEO and (b) U-PPO with THF and ethanol.

Table 2. Area under peaks of different $\mathrm{T}^{\mathrm{n}}$ species of ${ }^{29} \mathrm{Si} \mathrm{NMR}$ of monoliths and degree of polycondensation.

\begin{tabular}{|c|c|c|c|c|}
\hline \multirow{2}{*}{ Hybrid } & \multirow{2}{*}{ Solvent } & $\mathbf{T}^{2}$ area & $\mathrm{T}^{3}$ area & \multirow{2}{*}{$\begin{array}{c}\text { Degree of } \\
\text { Polycondensation (\%) }\end{array}$} \\
\hline & & $\%$ & $\%$ & \\
\hline \multirow{2}{*}{ U-PEO500 } & THF & 34 & 65 & 88 \\
\hline & Ethanol & 41 & 59 & 86 \\
\hline \multirow{2}{*}{ U-PEO1900 } & THF & 27 & 72 & 90 \\
\hline & Ethanol & 17 & 82 & 94 \\
\hline \multirow{2}{*}{ U-PPO400 } & THF & 27 & 73 & 91 \\
\hline & Ethanol & 22 & 78 & 92 \\
\hline \multirow{2}{*}{ U-PPO2000 } & THF & 24 & 76 & 92 \\
\hline & Ethanol & 26 & 73 & 90 \\
\hline
\end{tabular}

\subsubsection{Thermal analysis}

Figure 7 shows the DSC curves for di-ureasil monoliths prepared as previously described. The DSC data for U-PEO1900 showed an endothermic peak between $25-27^{\circ} \mathrm{C}$ related to the melting of the crystalline phase present in the materials. In these polymers, the appearance of regions or crystalline domains surrounded by an amorphous disordered phase and characterizing the formation of a semi-crystalline polymer is well related in the scientific literature ${ }^{8,9,11}$. The negative glass transition temperature for all U-PEO and U-PPO monoliths is related to the high flexibility of di-ureasil polymers, as has been previously reported in the 
literature ${ }^{8,11}$. U-PPO400 both in THF and in ethanol, however, showed less negative values (- 10 with THF and -8 for ethanol) indicating that this matrix has a higher stiffness. This can be explained by the fact that these matrices have a larger number of Si-O-Si bonds due to both the low molecular weight of the polymeric chains and the high degree of polycondensation (see Figure 6), increasing the ratio ureasil groups/polymers ${ }^{11}$. This fact, associated with the methyl group present in the polymer chain of these matrices, contributed to the increased rigidity of the polymeric matrixes. This great rigidity for U-PPO 400 monoliths was also observed macroscopically and by the DMA data shown by Figure 7. Observed values of glass transition temperature $(\mathrm{Tg})$, melting point $(\mathrm{Tm})$ and enthalpy change $(\Delta \mathrm{H})$ obtained from DSC curves for the hybrids di-ureasil synthesized with THF and ethanol are presented in Table 3.
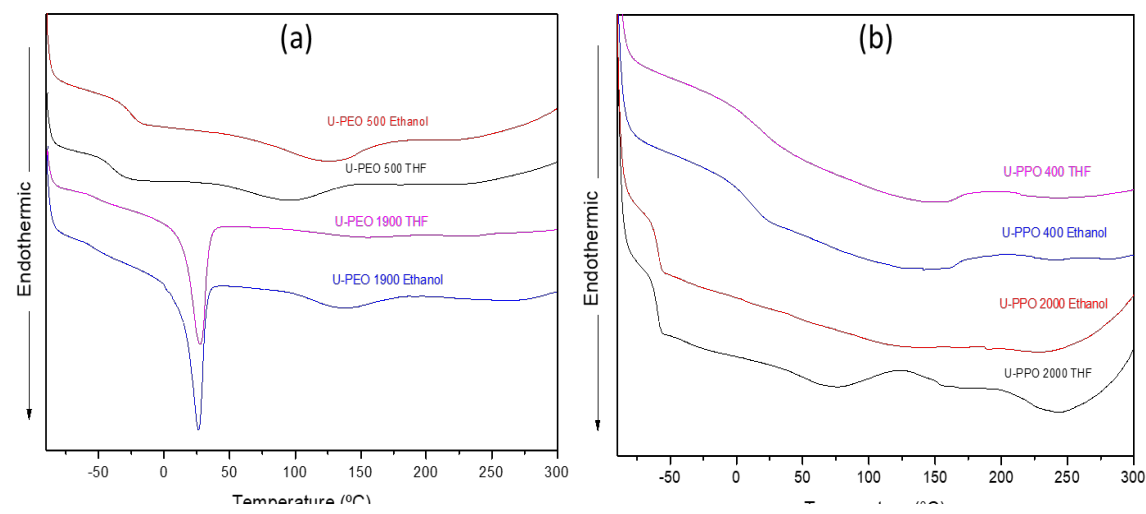

Figure 7. DSC curves of monoliths from di-ureasil precursors (a) U-PEO and (b) U-PPO with THF and ethanol.

Table 3. Data obtained from DSC curves for the hybrid ureasil PEO and PPO with THF and ethanol.

\begin{tabular}{|c|c|c|c|c|c|c|c|c|}
\hline & \multicolumn{2}{|c|}{ PEO 1900} & \multicolumn{2}{|c|}{ PEO 500} & \multicolumn{2}{|c|}{ PPO 2000} & \multicolumn{2}{|c|}{ PPO 400} \\
\hline & THF & ET & THF & ET & THF & ET & THF & ET \\
\hline $\operatorname{Tg}\left({ }^{\circ} \mathrm{C}\right)$ & -60 & -61 & -46 & -42 & -62 & -63 & -10 & -8 \\
\hline $\mathrm{Mp}\left({ }^{\circ} \mathrm{C}\right)$ & 26.47 & 25.87 & - & - & - & - & - & - \\
\hline$\Delta \mathrm{H}(\mathrm{J} / \mathrm{g})$ & 62.40 & 76.50 & - & - & - & & - & - \\
\hline
\end{tabular}

\subsubsection{Mechanical analysis}

The DMA data indicated that, after the application of a large force $(18 \mathrm{~N}=0.6 \mathrm{MPa})$, the samples were not damaged.

Figure 8 shows the comparative deformation curves for U-PPO400, U-PPO200, U-PEO500 and U-PEO1900, all synthesized in THF and ethanol.

Regardless of the solvent used, the values do not change. However, when we comparing the values between the different U-PPO or U-PEO groups, the degree of deformation was as follows: U-PPO400 $(\approx 15 \%)<$ up U-PEO1900 $(\approx 22 \%)<$ up U-PEO500 $(\approx 28 \%)$ and U-PPO2000 around $40 \%$. These data corroborate the DSC results, according to which U-PPO400 showed higher $\mathrm{Tg}$, revealing that these matrices are more rigid and therefore more resistant to deformation. Those are followed by the low and high molecular weight U-POE, which presented intermediate $\mathrm{Tg}$ values (between $-46^{\circ} \mathrm{C}$ and $-61^{\circ} \mathrm{C}$ ). Finally, the lowest $\mathrm{Tg}$ values were from the hybrid matrices ureasil-POP 2000, indicating that these matrices are more flexible and more easily deformable. 


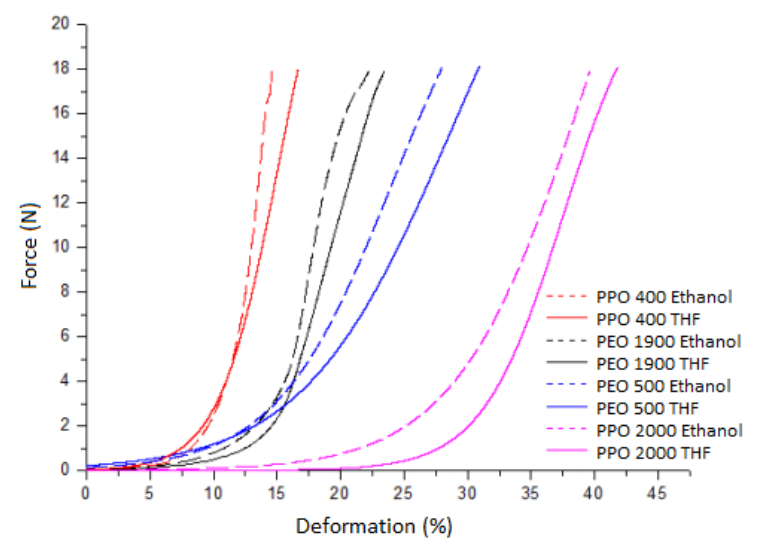

Figure 8. Strain curves as a function of force to hybrid matrices PEO and PPO.

\section{CONCLUSIONS}

This worked allowed to observe that the use of ethanol, instead of THF, to synthesize diureasil hybrids did not affect the structural characteristics, as well as the thermal and mechanical properties. Therefore, it is possible to obtain the same material while maintaining its desirable characteristics such as transparency, mechanical strength and low water solubility, but using a cheaper, more accessible and less toxic solvent.

\section{ACKNOWLEDGMENTS}

FAPESP - Fundação de Amparo à Pesquisa do Estado de São Paulo or Foundation for Research Support of the State of São Paulo, process number 2017/21456-3.

CAPES - Coordenação de Aperfeiçoamento de Pessoal de Nível Superior - Brasil (CAPES) Finance Code 001.

CNPQ - Conselho Nacional de Desenvolvimento Científico e Tecnológico or National Council for Scientific and Technological Development

\section{REFERENCES}

1. Fenton OS, Olafson KN, Pillai PS, Mitchell MJ, Langer R. Advances in biomaterials for drug delivery. Adv Mater. 2018;30(29):1-29. http://dx.doi.org/10.1002/adma.201705328.

2. Kamaly N, Yameen B, Wu J, Farokhzad OC. Degradable controlled-release polymers and polymeric nanoparticles: mechanisms of controlling drug release. Chem Rev. 2016;116(4):2602-63. http://dx.doi.org/10.1021/acs.chemrev.5b00346. PMid:26854975.

3. Aghabegi Moghanjoughi A, Khoshnevis D, Zarrabi A. A concise review on smart polymers for controlled drug release. Drug Deliv Transl Res. 2016;6(3):333-40. http://dx.doi.org/10.1007/s13346015-0274-7. PMid:26744179.

4. Venditti I. Morphologies and functionalities of polymeric nanocarriers as chemicaltools for drug delivery: A review. J King Saud Univer - Sci. 2019;31:398-411.

5. Yun YH, Lee BK, Park K. Controlled drug delivery: historical perspective for the next generation. J Control Release. 2015;219:2-7. http://dx.doi.org/10.1016/j.jconrel.2015.10.005. PMid:26456749.

6. Wu PC, et al. Graphene oxide conjugated with polymers: a study of culture condition to determine whether a bacterial growth stimulant or an antimicrobial agent? J Nanobiotechnology. 2018;16(1):1. http://dx.doi.org/10.1186/s12951-018-0392-8. PMid:29321058.

7. Mir SH, Nagahara LA, Thundat T, Mokarian-Tabari P, Furukawa H, Khosla A. Review-organicinorganic hybrid functional materials: an integrated platform for applied technologies. J Electrochem Soc. 2018;165(8):3137-56. http://dx.doi.org/10.1149/2.0191808jes.

8. Molina EF, Pulcinelli SH, Briois V, Santilli CV. Fine-tuning of a nanostructure, swelling, and drug delivery profile by blending ureasil-PEO and ureasil-PPO hybrids. Polym Chem. 2014;5(6):1897904. http://dx.doi.org/10.1039/C3PY01126G. 
9. Santilli CV, Chiavacci LA, Lopes L, Pulcinelli SH, Oliveira AG. Controlled drug release from ureasil-polyether hybrid materials. Chem Mater. 2009;21(3):463-7. http://dx.doi.org/10.1021/cm801899u.

10. José NM, Prado LASA. Materiais híbridos orgânico-inorgânicos: preparação e algumas aplicações. Quim Nova. 2005;28(2):281-8. http://dx.doi.org/10.1590/S0100-40422005000200020.

11. Lopes L, Molina EF, Chiavacci LA, Santilli CV, Briois V, Pulcinelli SH. Drug-matrix interaction of sodium diclofenac incorporated into ureasil-poly(ethylene oxide) hybrid materials. RSC Advances. 2012;2(13):5629-36. http://dx.doi.org/10.1039/c2ra01216b.

12. Jesus CRN, Molina EF, Pulcinelli SH, Santilli CV. Highly controlled diffusion drug release from ureasilpoly(ethylene oxide)- $\mathrm{Na}^{+}$-montmorillonite hybrid hydrogel nanocomposites. ACS Appl Mater Interfaces. 2018;10(22):19059-68. http://dx.doi.org/10.1021/acsami.8b04559. PMid:29749723.

13. Joshi DR, Adhikari N. An overview on common organic solvents and their toxicity. JPRI. 2019;28:118. http://dx.doi.org/10.9734/jpri/2019/v28i330203.

14. Hu D, et al. Performance of a pilot split-type anaerobic membrane bioreactor (AnMBR) treating antibiotics solvent wastewater at low temperatures. Chem Eng J. 2017;325:502-12. http://dx.doi.org/10.1016/j.cej.2017.05.086.

15. Ong CN, Chia SE, Phoon WH, Tan KT. Biological monitoring of occupational exposure to tetrahydrofuran. Br J Ind Med. 1991;48(9):616-21. http://dx.doi.org/10.1136/oem.48.9.616. PMid:1911404.

16. Chiavacci LA, Dahmouche K, Silva NJO, Carlos LD, Amaral VS, De Zea Bermudez V, Pulcinelli SH, Santilli CV, Briois V, Craievich AF. Effect of presence of an acid catalyst on structure and properties of iron-doped siloxane-polyoxyethylene nanocomposites prepared by sol-gel. J Non-Cryst Solids. 2004;345/346:585-90. http://dx.doi.org/10.1016/j.jnoncrysol.2004.08.089.

\section{Authors' contributions}

J.F. Mendes. - First author, Substantial contributions to the acquisition, analysis and interpretation of data; J.A. Oshiro-Jr. - Co-author, Substantial contributions to the conception and design of the work, analysis and interpretation of data; C.G. da Silva - Co-author, Substantial contributions to the analysis and interpretation of data and drafting the work or revising it critically for important intellectual content; L.A. Chiavacci. - Corresponding Author, Substantial contributions to the conception and design of the work, to the acquisition, analysis and interpretation of data and drafting the work or revising it critically for important intellectual content. 